\title{
Genetic testing for coarctation of aorta
}

\author{
Yeltay Rakhmanov ${ }^{1}$, Paolo Enrico Maltese ${ }^{1 \star}$, Alessandra Zulian ${ }^{2}$, Tommaso Beccari ${ }^{3}$, Munis Dundar ${ }^{4}$ \\ and Matteo Bertelli1,2
}

\begin{abstract}
Coarctation of the aorta ( $\mathrm{CoA})$ is an inherited narrowing of the proximal descending thoracic aorta. Histological features include localized medial thickening and infolding with superimposed neointimal tissue. CoA is diagnosed by detection of a murmur or hypertension during routine examination. Typical clinical features are delayed or absent femoral pulses and difference in blood pressure between the arm and legs. These symptoms may appear in the first weeks of life or after the neonatal period. CoA accounts for 4-6\% of all congenital heart defects and has a reported prevalence of about 4 per 10,000 live births. It is more common in males than females (59\% vs $41 \%$ ). This Utility Gene Test was developed on the basis of an analysis of the literature and existing diagnostic protocols. It is useful for confirming diagnosis, as well as for differential diagnosis, couple risk assessment and access to clinical trials.
\end{abstract}

Keywords: Coarctation of Aorta, EBTNA UTILITY GENE TEST

'MAGI's Lab, Rovereto, Italy

2MAGI Euregio, Bolzano, Italy

${ }^{3}$ Department of Pharmaceutical Sciences, University of Perugia, Perugia, Italy

${ }^{4}$ Department of Medical Genetics, Erciyes University Medical School, Kayseri, Turkey

*Corresponding author: P. E. Maltese E-mail: paolo.maltese@assomagi.org

DOI: 10.2478/ebtj-2018-0041
C 2018 Authors. This work was licensed under the Creative Commons AttributionNonCommercial-NoDerivs 3.0 License.

\section{Coarctation of aorta}

(Other synonym: Aortic coarctation)

\section{General information about the disease}

Coarctation of the aorta $(\mathrm{CoA})$ is a congenital narrowing of the proximal descending thoracic aorta (1). The defect is typically located immediately distal to the origin of the left subclavian artery, at or adjacent the insertion of the ductus arteriosus, although obstruction may occur anywhere in the aortic arch (2). Histological features include localized medial thickening and infolding with superimposed neointimal tissue. This thickening may be discrete (shelf-like) or may more commonly involve a large portion of the juxtaductal aorta (2-5).

CoA is diagnosed by detection of a murmur or hypertension during routine examination. Typical clinical features are delayed or absent femoral pulses and a difference of $20 \mathrm{~mm}$ $\mathrm{Hg}$ or more in blood pressure between the arm and legs (6). Clinical presentation and severity of symptoms depend on associated defects and aortic arch anomalies, the extent of patency of the ductus arteriosus, the speed of closure of the ductus arteriosus, and the degree of pulmonary vascular resistance. These symptoms may appear in the first weeks of life or after the neonatal period (7-8).

Boon et al. observed a familial pattern of CoA and other congenital heart defects compatible with multifactorial inheritance. Recurrence risk for siblings was approximately 1 in 200 for coarctation of the aorta, and $1 \%$ for all congenital heart defects. The heritability of coarctation is estimated at $58 \%$ (9). CoA accounts for $4-6 \%$ of all congenital heart defects with a reported prevalence of about 4 per 10,000 live births $(10,11)$. It is more common in males than females (59\% versus $41 \%$ ) (12).

Diagnosis is based on clinical assessment to identify symptoms, echocardiogram, 
electrocardiogram, chest radiogram, color Doppler with twodimensional echocardiography, spin-echo MR imaging, CT, diagnostic catheterization and genetic testing.

Differential diagnosis should consider aortic valve stenosis, interruption of the aortic arch, and hypoplastic left heart syndrome.

An abundance of large X-chromosome copy number variations in affected males was recently proposed as a factor in the development of syndromic and non-syndromic CoA (13).

Non-syndromic CoA has autosomal dominant inheritance with high penetrance and variable expressivity (14).

Likely candidate genes for autosomal dominant nonsyndromic CoA (OMIM disease 120000)

- NOTCH1 (OMIM gene 190198) (15);

- MCTP2 (OMIM gene 616297) (16).

Autosomal dominant CoA-associated syndromic disorders

- Noonan Syndrome 1 (NS1, OMIM disease 163950) PTPN11 (OMIM gene 176876);

- Kabuki syndrome 1 (KABUK1, OMIM disease 147920) KMT2D (OMIM gene 602113);

- Myhre syndrome (MYHRS, OMIM disease 139210) SMAD4 (OMIM gene 600993);

- Floating-Harbor syndrome (FLHS, OMIM disease 136140) - SRCAP (OMIM gene 611421).

Autosomal recessive $\mathrm{CoA}$-associated syndromic disorders

- Congenital heart defects, hamartomas of tongue, and polysyndactyly syndrome (CHDTHP, OMIM disease 217085) - WDPCP (OMIM gene 613580).

Pathogenic variants may include missense, small deletions and insertions, small indels and gross insertions and deletions.

\section{Aims of the test}

- To determine the gene defect responsible for the disease;

- To confirm clinical diagnosis;

- To assess the recurrence risk and perform genetic counselling for at-risk/affected individuals.

\section{Test characteristics}

\section{Specialist centers/ Published Guidelines}

The test is listed in the Orphanet database and is offered by 1 accredited medical genetic laboratories in the EU, and in the GTR database, offered by 1 accredited medical genetic laboratories in the US.

Guidelines for clinical use of the test are described in $\mathrm{Ge}$ netics Home Reference (ghr.nlm.nih.gov).

\section{Test strategy}

Clinically distinguishable syndromes can be analyzed by sequencing only those genes known to be associated with that specific disease using Sanger or Next Generation Sequencing
(NGS); if the results are negative, or more generally if clinical signs are ambiguous for diagnosis, a multi-gene NGS panel is used to detect nucleotide variations in coding exons and flanking introns of the above genes.

Potentially causative variants and region with low coverage are Sanger-sequenced. Sanger sequencing is also used for family segregation studies.

Multiplex Ligation Probe Amplification (MLPA) is used to detect duplications and deletions in KMT2D gene.

To perform molecular diagnosis, a single sample of biological material is normally sufficient. This may be $1 \mathrm{ml}$ peripheral blood in a sterile tube with $0.5 \mathrm{ml} \mathrm{K}$ EDTA or $1 \mathrm{ml}$ saliva in a sterile tube with $0.5 \mathrm{ml}$ ethanol $95 \%$. Sampling rarely has to be repeated.

Gene-disease associations and the interpretation of genetic variants are rapidly developing fields. It is therefore possible that the genes mentioned in this note may change as new scientific data is acquired. It is also possible that genetic variants today defined as of "unknown or uncertain significance" may acquire clinical importance.

\section{Genetic test results \\ Positive}

Identification of pathogenic variants in the above genes confirms the clinical diagnosis and is an indication for family studies.

A pathogenic variant is known to be causative for a given genetic disorder based on previous reports, or predicted to be causative based on loss of protein function or expected significant damage to proteins or protein/protein interactions. In this way it is possible to obtain a molecular diagnosis in new/other subjects, establish the risk of recurrence in family members and plan preventive and/or therapeutic measures.

\section{Inconclusive}

Detection of a variant of unknown or uncertain significance (VUS): a new variation without any evident pathogenic significance or a known variation with insufficient evidence (or with conflicting evidence) to indicate it is likely benign or likely pathogenic for a given genetic disorder. In these cases, it is advisable to extend testing to the patient's relatives to assess variant segregation and clarify its contribution. In some cases, it could be necessary to perform further examinations/tests or to do a clinical reassessment of pathological signs.

\section{Negative}

The absence of variations in the genomic regions investigated does not exclude a clinical diagnosis but suggests the possibility of:

- alterations that cannot be identified by sequencing, such as large rearrangements that cause loss (deletion) or gain (duplication) of extended gene fragments;

- sequence variations in gene regions not investigated by this test, such as regulatory regions (5' and 3' UTR) and deep intronic regions; 
- variations in other genes not investigated by the present test.

\section{Unexpected}

Unexpected results may emerge from the test, for example information regarding consanguinity, absence of family correlation or other genetically-based diseases.

\section{Risk for progeny}

If the identified pathogenic variant has autosomal dominant transmission, the probability that an affected carrier transmit the disease variant to his/her children is $50 \%$ in any pregnan$c y$, irrespective of the sex of the child conceived.

In autosomal recessive mutations, both parents are usually healthy carriers. In this case, the probability of transmitting the disorder to the offspring is $25 \%$ in any pregnancy of the couple, irrespective of the sex of the child. An affected individual generates healthy carrier sons and daughters in all cases, except in pregnancies with a healthy carrier partner. In these cases, the risk of an affected son or daughter is $50 \%$.

Incomplete penetrance and/or variable expressivity may influence the manifestation of clinical symptoms in individuals harboring disease-causing variations.

\section{Limits of the test}

The test is limited by current scientific knowledge regarding the gene and disease.

Analytical sensitivity (proportion of positive tests when the genotype is truly present) and specificity (proportion of negative tests when the genotype is not present)

NGS: Analytical sensitivity $>99.99 \%$, with a minimum coverage of 10X; Analytical specificity 99.99\%.

SANGER: Analytical sensitivity $>99.99 \%$; Analytical specificity $99.99 \%$.

MLPA: Analytical sensitivity >99.99\%; Analytical specificity 99.99\%.

\section{Clinical sensitivity (proportion of positive tests} if the disease is present) and clinical specificity (proportion of negative tests if the disease is not present)

Clinical sensitivity: variations in the aforementioned genes are associated with CoA, but may be individual variations (identified in one or a few families) and total epidemiological data is therefore not available.

Clinical specificity is estimated at approximately $99 \%$ (17).

\section{Prescription appropriateness}

The genetic test is appropriate when:

a) the patient meets the diagnostic criteria for $\mathrm{CoA}$;

b) the sensitivity of the test is greater than or equal to that of tests described in the literature.

\section{Clinical utility}

\section{Clinical management}

Utility

Confirmation of clinical diagnosis

Yes

Differential diagnosis Yes

Couple risk assessment Yes

Availability of clinical trials can be checked on-line at https://clinicaltrials.gov/

\section{References}

1. LaDisa JF, Bozdag S, Olson J, Ramchandran R, Kersten JR, Eddinger TJ. Gene Expression in Experimental Aortic Coarctation and Repair: Candidate Genes for Therapeutic Intervention. Esteban FJ, ed. PLoS ONE 2015; 10(7): e0133356.

2. Usman MH, Rengifo-Moreno P, Janzer SF, Inglessis-Azuaje I, Witzke-Sanz C. Coarctation of the aorta: management, indications for intervention, and advances in care. Curr Treat Options Cardiovasc Med 2014; 16(10): 341.

3. Folger GM Jr, Stein PD. Bicuspid aortic valve morphology when associated with coarctation of the aorta. Cathet Cardiovasc Diagn 1984; 10(1): 17-25.

4. Shone JD, Sellers RD, Anderson RC, Adams P Jr, Lillehei CW, Edwards JE. The developmental complex of "parachute mitral valve," supravalvular ring of left atrium, subaortic stenosis, and coarctation of aorta. Am J Cardiol 1963; 11: 714-25.

5. Machii M, Becker AE. Nature of coarctation in hypoplastic left heart syndrome. Ann Thorac Surg 1995; 59(6): 1491-94.

6. Rao PS. Coarctation of the aorta. Curr Cardiol Rep 2005; 7(6): 42534.

7. Rao PS. Balloon angioplasty of native aortic coarctation. J Am Coll Cardiol 1992; 20(3): 750-51.

8. Salahuddin N, Wilson AD, Rao PS. An unusual presentation of coarctation of the aorta in infancy: role of balloon angioplasty in the critically ill infant. Am Heart J 1991; 122(6): 1772-75.

9. Boon AR, Roberts DF. A family study of coarctation of the aorta. Journal of Medical Genetics 1976; 13(6): 420-33.

10. Reller MD, Strickland MJ, Riehle-Colarusso T, Mahle WT, Correa A. Prevalence of congenital heart defects in metropolitan Atlanta, 1998-2005. J Pediatr 2008; 153(6): 807-13.

11. Hoffman JI, Kaplan S. The incidence of congenital heart disease. J Am Coll Cardiol 2002; 39(12): 1890-00.

12. Fyler DC, Buckley LP, Hellenbrand WE, Cohn, H.E., Kirklin, J.W., Nadas, A.S. Report of the New England Regional Infant Cardiac Program. Pediatrics 1980; 65(2 Pt 2): 375-61.

13. Moosmann J, Uebe $S$, Dittrich $S$, Rüffer A, Ekici AB, Toka O. Novel loci for non-syndromic coarctation of the aorta in sporadic and familial cases. PLoS One 2015; 10(5): e0126873

14. Beekman RH, Robinow M. Coarctation of the aorta inherited as an autosomal dominant trait. Am J Cardiol 1985; 56(12): 818-19.

15. Freylikhman O, Tatarinova T, Smolina N, Zhuk S, Klyushina A, Kiselev A, Moiseeva O, Sjoberg G, Malashicheva A, Kostareva A. Variants in the NOTCH1 gene in patients with aortic coarctation. Congenit Heart Dis 2014; 9(5): 391-96.

16. Lalani SR, Ware SM, Wang X, Zapata G, Tian Q, Franco LM, Jiang $Z$, Bucasas K, Scott DA, Campeau PM, Hanchard N, Umaña L, Cast A, Patel A, Cheung SW, McBride KL, Bray M, Craig Chinault $A$, Boggs BA, Huang M, Baker MR, Hamilton S, Towbin J, Jefferies JL, Fernbach SD, Potocki L, Belmont JW. MCTP2 is a dosage-sensitive gene required for cardiac outflow tract development. Hum Mol Genet 2013; 22(21): 4339-48.

17. Chen B, Gagnon M, Shahangian S, Anderson NL, Howerton DA, Boone JD; Centers for Disease Control and Prevention (CDC). Good Laboratory Practices for Molecular Genetic Testing for Heritable Diseases and Conditions. MMWR Recomm Rep 2009; 58(RR6): 1-37. 